\title{
Properties and application of coatings sprayed with cold gas
}

\begin{abstract}
Keywords:

cold gas spraying;

titanium;

mechanical properties

Cold spraying is new technology which allows to obtain coatings with properties which are unobtainable by previously used thermal spray methods. This technology can be also used in the area of additive manufacturing. The article presents findings of microstructure and mechanical properties of cold-sprayed titanium structures on Al 7075 aluminum alloy.
\end{abstract}

\section{Introduction}

Currently, the greatest potential for innovation in surface engineering technologies is provided by thermal spraying techniques. These include a group of processes that allows deposition of the particulate material in a molten, thermoplastic or solid state on the substrate to form a coating. The special possibilities of depositing coatings with new properties are created by cold gas spraying, where the adverse effect of heat on the coating material has been eliminated. Spraying with cold gas was the result of experiments conducted by a team of prof. A. Papyrina at the Institute of Theory and Applied Mechanics in Novosibirsk. The process involves heating up to $1100{ }^{\circ} \mathrm{C}$ of compressed gas to $7 \mathrm{MPa}$ and then directing it to the DeLavala nozzle. In the divergent part of the nozzle, the gas accelerates to supersonic velocity $(2 \div 4 \mathrm{Ma})$. The above mentioned technique enables the application of metal and cermet coatings with unique properties $[1 \div 3]$. The coatings are deposited only using the kinetic energy of the gas stream. The main advantages of cold gas sprayed coatings are high purity and excellent physical properties, which creates many new possibilities for unconventional applications. The range of materials used in the cold gas spraying process includes pure metals $(\mathrm{Cu}, \mathrm{Ag}, \mathrm{Al}, \mathrm{Sn}, \mathrm{Zn}, \mathrm{Ni}, \mathrm{Ta}, \mathrm{Ti})$, alloys and cermets. This spraying method allows the deposition of not only coatings, but it can also be used in incre-

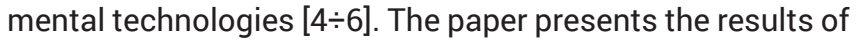
research on cold gas-sprayed titanium structure in the Surface Engineering Laboratory of Centre for Laser Technologies of Metals of Kielce University of Technology, where a robotic system for cold gas spraying Impact Innovation $5 / 8$ is located (Fig. 1). The possibilities of using cold gas spraying in incremental technologies have been shown.

\section{Research methodology}

The titanium structure (understood as a macroscopic spatial creation) with a diameter of $\varnothing 55.5 \mathrm{~mm}$ was sprayed with cold gas on a sleeve with a diameter of $\varnothing 25$ made of Al 7075 alloy (Fig. 2). The purchased non-spheroidal titanium powder with granulation of $-65+15 \mu \mathrm{m}$ was used. The microstructure analysis of the sprayed coating and its linear analysis were performed using the Jeol JSM 7100F scanning microscope and the ISIS 300 Oxford microprobe (EDS). Phase analysis of the powder and titanium structure was performed using a Bruker D8 Discover diffractometer (Co Ka radiation). The tests of mechanical properties were carried out using the method of indentation using the Nanove's system with Berkovich

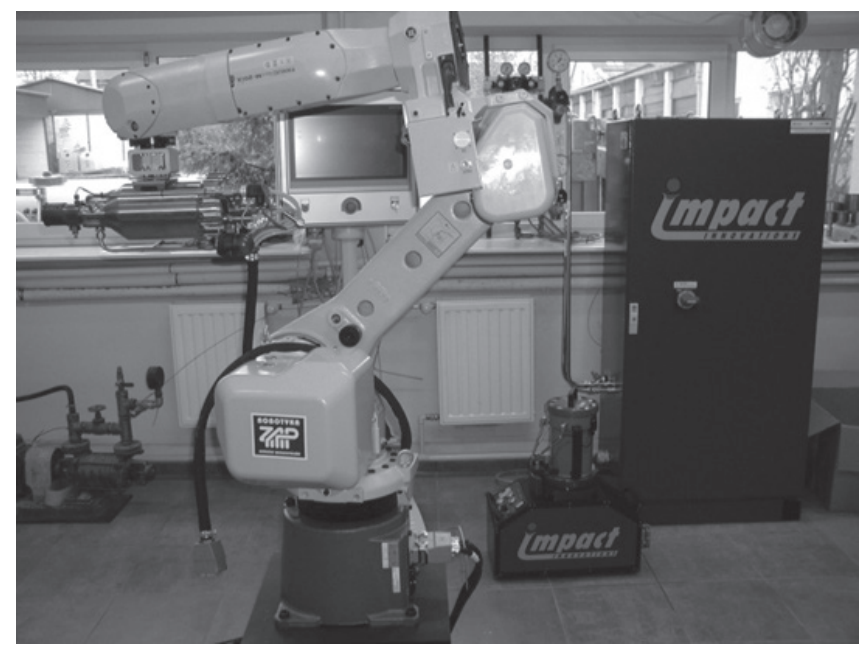

Fig. 1. High-pressure cold gas spraying system - Impact Innovation 5/8

dr hab. inż. Wojciech Żórawski, prof. PŚk; dr Medard Makrenek; mgr inż. Dominika Soboń - Kielce University of Technology; 


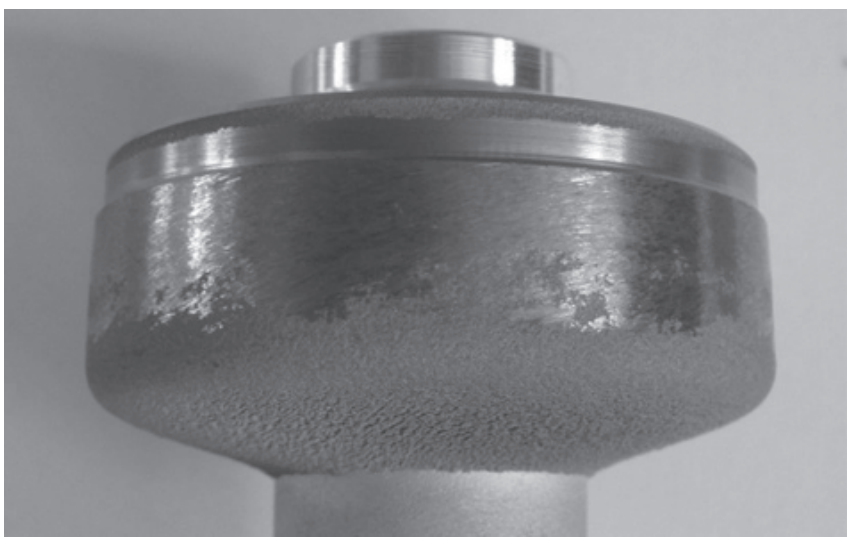

Fig. 2. Titanium structure sprayed with cold gas

indenter and a load of $40 \mathrm{mN}$ (Olivier-Pharr method). 49 measurements were carried out in a square area with $240 \mu \mathrm{m}$ side ( $40 \mu \mathrm{m}$ stroke) in the center of the sprayed structure.

\section{Research results and discussion}

The morphology of Ti grains and their etched metallographic specimen is shown in Figure 3.

Irregular shape of Ti powder grains is visible, which is similar to polyhedral. There is a significant variation in grain size, which results from the use of HDH (hydrogenation-dehydrogenation) for its production (Fig. 3a). On the etched metallographic specimen of the powder grains, their small porosity is visible (Fig. 3b).
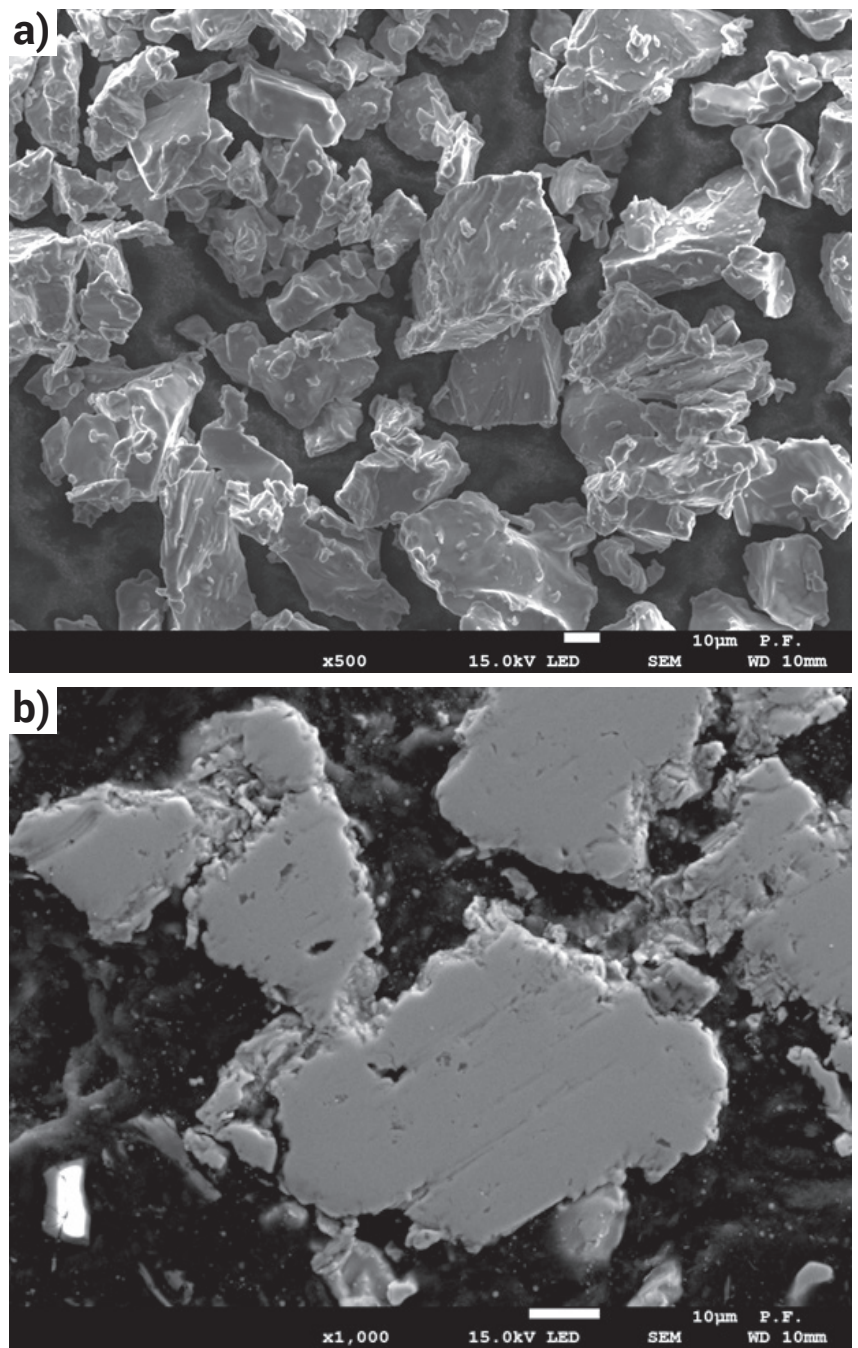

Fig. 3. Morphology of Ti powder (a) and metallographic specimen of grains (b)
Cold gas sprayed titanium microstructure is shown in $\mathrm{Fi}$ gure 4 . The sprayed titanium grains, despite their irregular shape and considerable size differentiation, created a very high density coating, and the particles deformed under the impact strongly adhere to each other (Fig. 4a). At high magnification, small pores are visible at the border of deformed powder grains (Fig. 4b).

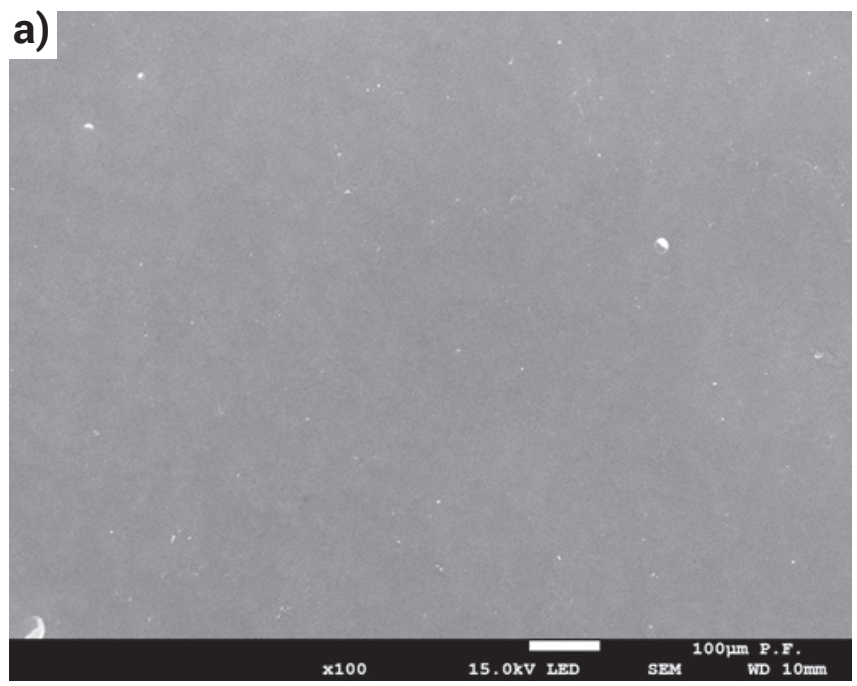

b)

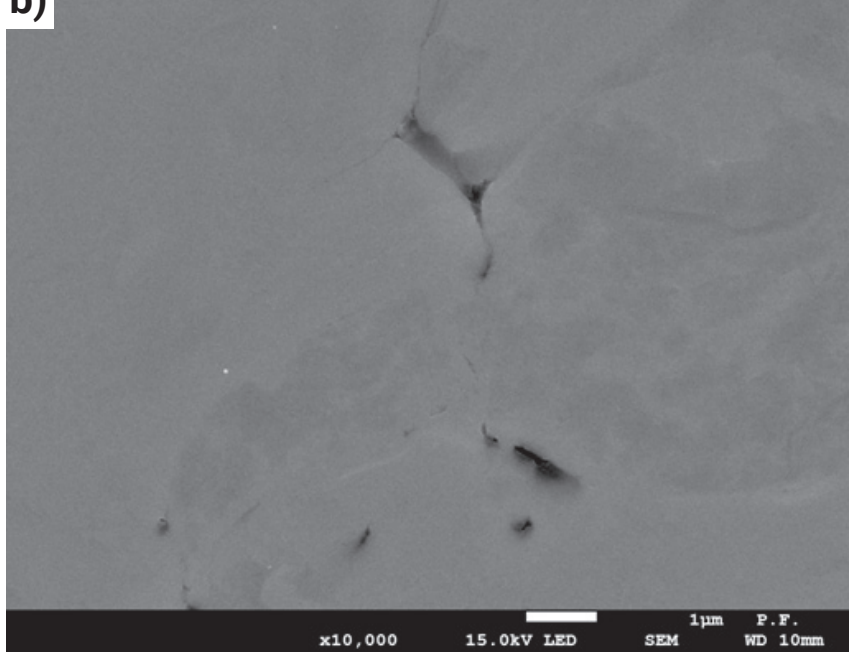

Fig. 4. Titanium microstructure sprayed with cold gas: a) 100x, b) $10000 x$

Figure 5 presents the results of the phase composition testing of the titanium powder used and the cold gas sprayed structure. Both the powder and the sprayed structure consist only of pure titanium. During the spraying process, no chemical reactions took place, which would create new phases in the structure being sprayed.

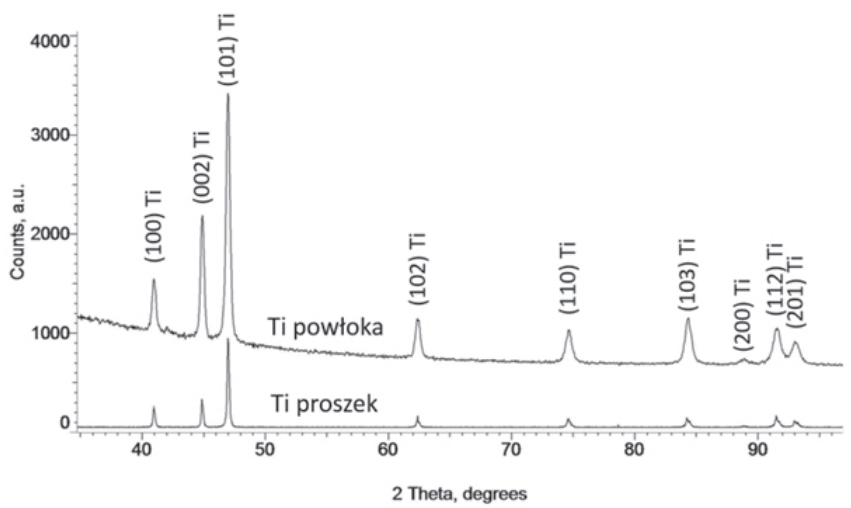

Fig. 5. Phase analysis of titanium powder and cold gas sprayed structure 
The results of the nanoindentation tests of the titanium structure are shown in Figure 6. There is a significant variation in the mechanical properties of the structure being sprayed (nanohardness and Young's modulus). This is the result of varying degrees of deformation of the titanium powder grains, which are of various sizes and at the moment of impact on the substrate have different speed. The coating hardness was $3.0 \pm 0.6 \mathrm{GPa}$ and Young's modulus was $134.3 \pm 17.5 \mathrm{GPa}$.
Cold gas sprayed structures can be used in incremental technologies. Of particular interest is the use of titanium and its alloys in the aerospace industry both for the production of new parts and for regeneration $[7 \div 10]$. The scope of application of this technology creates new possibilities, also in the area of nuclear energy for the production of neutron shields [11].
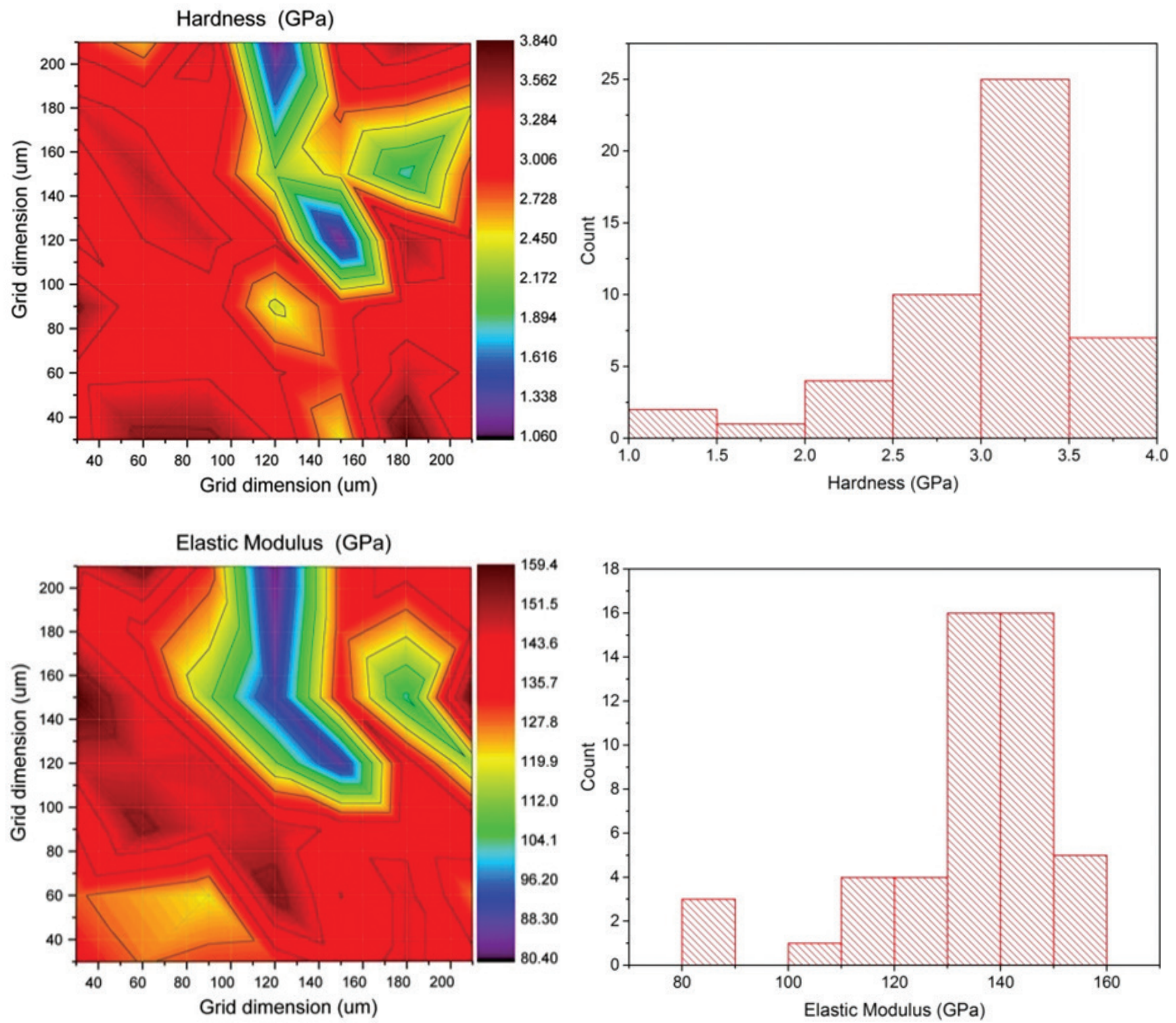

Fig. 6. Mechanical properties of the titanium structure: a) hardness distribution map, b) hardness histogram, c) Young's modulus distribution chart, d) Young's modulus histogram

\section{Conclusions}

The cold gas spraying process makes it possible to obtain titanium structures. The titanium microstructure consists of deformed powder grains that strongly adhere to each other. The presence of a small amount of small pores visible at high magnification was found. During the cold gas spraying process, there were no phase changes in the sprayed powder and the coating consisted exclusively of titanium. Analysis of the nanoindentation results of the titanium structure showed a significant variation in its mechanical properties.

The authors would like to thank Mrs. Anna Góral, PhD. Eng., for performing phase composition tests. Work financed from funds for education of NCBiR as part of the Innolot program.

„Badania technologii przyrostowych i procesów hybrydyzacji obróbki dla potrzeb rozwoju innowacyjnej produkcji lotniczej”. 


\section{References}

[1] A. Papyrin, Cold Spraying, Elsewier Ltd. 2007.

[2] C.M. Kay, J. Karthikeyan, High Pressure Cold Spray, ASM International 2016.

[3] J. Villafuerte, Modern Cold Spray, Materials, Process and Applications, Springer 2015.

[4] H. Assadi, H. Kreye, F. Gartner, T. Klassen, Cold spraying - A materials perspective. Acta Materialia 116 (2016) 382-407.

[5] R.N. Raoelison, Ch. Verdy, H. Liao, Cold gas dynamic spray additive manufacturing today, Deposit possibilities, technological solutions and viable applications, Materials and Design 133 (2017) 266-287.

[6] J. Villafuerte, Considering Cold Spray for Additive Manufacturing, Advanced Materials \& Processes 50, May 2014, 50-52.

[7] Q. Blochet, F. Delloro, F. N'Guyen, D. Jeulin, F. Borit, M. Jeandin, Effect of the Cold-Sprayed Aluminum Coating-Substrate Interface Morphology on Bond Strength for Aircraft Repair Application, Journal of Thermal Spray Technology, (2017) 26:671-686.

[8] J. W. Murray, M. V. Zuccoli, T. Hussain, Heat Treatment of Cold-Sprayed C355 Al for Repair. Microstructure and Mechanical Properties, Journal of Thermal Spray Technology 2018) 27:159-168.

[9] Wenya Lia, Kang Yanga, Shuo Yin, Xiawei Yang, Yaxin Xu, Rocco Lupoi, Solid-state additive manufacturing and repairing by cold spraying: A review, Journal of Materials Science \& Technology, 34, 3(2018) 440-457.

[10] K. Petrackova, J. Kondas, M. Guagliano, Mechanical Performance of Cold-Sprayed A357 Aluminum Alloy Coatings for Repair and Additive Manufacturing, Journal of Thermal Spray Technology, (2017) 26:1888-1897.

[11] N.H. Tariq, L. Gyansah, J.Q. Wang, X. Qiu, B. Feng, M.T. Siddique, T.Y. Xiong, Cold spray additive manufacturing: A viable strategy to fabricate thick B4C/Al composite coatings for neutron shielding applications, Surface \& Coatings Technology 339 (2018) 224-236. 